\title{
Impact of halides on the simultaneous separation of aromatic amines and their acidic metabolites by capillary electrophoresis with laser-induced native fluorescence detection under acidic conditions
}

\author{
Ming-Mu Hsieh ${ }^{\mathrm{a}, *}$, Huan-Tsung Chang ${ }^{\mathrm{b}}$ \\ a Department of Applied Chemistry, Fooyin University, 151 Chin-Hsueh Road, Ta-Liao Hsiang, 831 Kaohsiung Hsien, Taiwan \\ ${ }^{\mathrm{b}}$ Department of Chemistry, National Taiwan University, Taipei, Taiwan \\ Received 27 June 2005; received in revised form 28 October 2005; accepted 1 November 2005
}

\begin{abstract}
This paper describes a simple, sensitive, efficient, and rapid method for simultaneous analysis of biologically active amines and acids by capillary electrophoresis in conjunction with laser-induced native fluorescence detection (CE-LINF) using a diode pumped solid state nanolaser at $266 \mathrm{~nm}$. In order to optimize resolution of the amines that were prepared in $10.0 \mathrm{mM}$ formate-Tris (FT) solutions, $10.0 \mathrm{mM}$ FT solutions with and without containing halides were used to fill the capillary and reservoirs, respectively. The electrophoretic mobilities of tryptamine (TA) and serotonin (5-HT) at $\mathrm{pH} 4.0$ decrease with the increase in halide concentration $(0-10.0 \mathrm{mM})$. Taken together with a great effect of iodide than other halides, we suggest that the formation of ion pairs is a main contributor for altering the migration of the amines. In order to simultaneously analyze the amines and their metabolites (acids) at low pH, a high bulk EOF is required. The analysis of 10 anlytes including amines and acids was completed within $12 \mathrm{~min}$ by CE-LINF using a capillary treated with $0.5 \mathrm{M} \mathrm{NaOH}$ and then filled with $10.0 \mathrm{mM}$ FT solutions (pH 4.0) containing $10.0 \mathrm{mM}$ $\mathrm{KCl}$ prior to analysis. The limits of detection for TA and 5-hydroxyindole-3-acetic acid (5-HIAA) are 0.12 and $6.0 \mathrm{nM}$, respectively. The present method has been further validated by analyzing urine samples, with an RSD less than $3.1 \%$ (migration times) and $3.9 \%$ (concentration).
\end{abstract}

(C) 2006 Elsevier B.V. All rights reserved.

Keywords: Catecholamines; Capillary electrophoresis; Laser-induced fluorescence; Ion pairs

\section{Introduction}

The determination of biologically active amines such as dopamine (DA), epinephrine (E), serotonin (5hydroxytryptamine; 5-HT), and tryptamine (TA) in biological samples such as urine and blood is of considerable importance because they are important neurotransmitters in central and peripheral nervous systems. Improper regulation of neurotransmitters has been found to be associated with several neurological disorders, including Parkinson's disease, schizophrenia, anxiety disorders, and memory impairment [1-8]. In order to improve the sensitivity of the diagnoses of pheochromocytoma, neuroblastoma, and Parkinson's disease, techniques allowing simultaneous determination of the biologically active amines and their metabolites (acids) such as

\footnotetext{
* Corresponding author. Tel.: +886 7 7811151x604; fax: +88677826732 .

E-mail address: sc126@mail.fy.edu.tw (M.-M. Hsieh).
}

5-hydroxyindole-3-acetic acid (5-HIAA), homovanillic acid (HVA), and DL-vanillomandelic acid (VMA) are essential [9-11]. However, the determination of these analytes in complicated biological samples is difficult, mainly because of their similar structures and low concentrations $(\mu \mathrm{M}-\mathrm{nM})$.

Capillary electrophoresis (CE) has played an important role in modern separation and life science because of its high efficiency for almost any analytes, requiring minute sample and reagent volumes and short analysis times [12-16]. When CE with UV-vis absorption detection is applied, the sensitivity for most amines and their metabolites in biological samples such as urines and cerebrospinal fluids (CSF) is sometimes problematic. To detect low concentrations of the analytes, laser-induced fluorescence (LIF) detection is usually used in CE [17-22]. Frequently, derivatization that might cause the loss of resolution and needs a long reaction time is required for most analytes in CE-LIF. As a result of having intrinsic fluorescence, some of the biologically active amines and acids have been determined by CE with laser-induced native fluorescence (LINF) using a 
UV laser such as Nd:YAG laser at $266 \mathrm{~nm}[18,19]$. Owing to its high sensitivity and efficiency, CE-LINF has proven powerful for single-cell analysis [23,24]. CE-LINF using background electrolytes (BGEs) containing surfactants has been applied to simultaneous analysis of biologically active amines and acids [25]. However, on the basis of our own experiences, a high fluorescence background and quenching caused by Joule heating are problematic when BGE containing a high amount of surfactant is used. In addition, repeatability is not excellent due to Joule heating and adsorption of the solutes. To overcome these drawbacks, the separation of biologically active amines and acids by CE-LINF using $1.5 \%$ poly(ethylene oxide) (PEO) solution has been demonstrated [18]. The analytes prepared in $25 \mathrm{mM}$ Tris-borate (TB) solution slowed down and were stacked when migrated to PEO solution (200 mM TB, $\mathrm{pH} 9.0)$ as a result of a decreased electric field and increased resistance for the analyte, leading to improved sensitivity. We point out that at $15 \mathrm{kV}$ the current $(3.0 \mu \mathrm{A})$ in $25 \mathrm{mM} \mathrm{TB}(\mathrm{pH} \mathrm{10.0)}$ is lower than that $(20 \mu \mathrm{A})$ of $1.5 \%$ PEO that was prepared in $200 \mathrm{mM} \mathrm{TB}(\mathrm{pH} 9.0)$. In the presence of $\mathrm{PEO}$ and high concentration of TB solution, analyte adsorption is minimized, leading to great efficiency. This approach provides the limits of detection (LODs) at signal-tonoise ratio $(\mathrm{S} / \mathrm{N}) 3$ of sub $\mathrm{nM}$ and $\mathrm{pM}$ for serotonin without and with applying a stacking approach, respectively. More recently, simultaneous analysis of low concentrations of amines and acids has been performed by applying different BGEs that had various $\mathrm{pH}$, viscosity, and ionic strength, with optimized resolution and sensitivity [19].

It is difficult to simultaneously achieve high resolution and sensitivity for biologically active amines and acids under continuous buffer conditions because of a wide range of dissociation constants $\left(K_{\mathrm{a}}\right)$ among amines and acids and their $\mathrm{pH}$ dependence of fluorescence quantum yields. Owing to greater quantum yields for most analytes under acidic conditions, the analysis at low $\mathrm{pH}$ is favorable with respect to sensitivity. However, at low $\mathrm{pH}(<4.0)$, the electrophoretic mobilities (EPMs) of the acids are small. Because the analytes migrate against a small electroosmotic flow (EOF), the separation is slow. On the other hand, because of almost complete protonation at low $\mathrm{pH}$, the amines migrate fast in the same direction of EOF. As a result, the resolution for some adjacent amines is poor. One other problem is irreproducibility due to analyte adsorption on the capillary wall. A number of CE approaches have been suggested for minimizing analyte adsorption as well as controlling EOF and/or the EPM of the analytes, including use of organic solvents [26-28] and polymers that are covalently attached to the capillary wall $[29,30]$. Recently, we have demonstrated the analysis of large volumes of biologically active amines and acids under discontinuous systems [19]. This stacking and separation approach provides the concentration LODs of 0.27 and $0.31 \mathrm{nM}$ at signalto-noise $(\mathrm{S} / \mathrm{N})=3$ for 5-HT and 5-HIAA, respectively, when the sample was injected at $15 \mathrm{kV}$ for $360 \mathrm{~s}$. The drawbacks of this approach include an unstable baseline, loss of sensitivity as $\mathrm{pH}$ increases during separation, and the need for regenerating a high bulk EOF after each run. In order to simultaneously analyze biologically active amines and acids as well as to achieve high sensitivity, $10.0 \mathrm{mM}$ formic acid solutions $(\mathrm{pH}<4.0)$ contain- ing silica nanoparticles (SiNPs) were chosen as the BGE [31]. That study shows that CE-LINF using nanoparticles is sensitive (the limits of detection of $0.09 \mathrm{nM}$ at $\mathrm{S} / \mathrm{N}=3$ for TA), highly efficient, and reproducible. However, the separation is slow.

The aim of this study is to develop a simple, highly efficient, fast, sensitive, and reproducible CE-LINF method for simultaneous determination of biologically active amines and acids. To achieve this goal, we conducted the analysis in the presence of a long plug of halide solution under acidic conditions. In order to form ion pairs between the analytes and halides, the capillary was filled with FT solutions containing halides. The formation of ion pairs caused varying degrees of the decreases in the EPM of the biologically active amines, leading to better resolution. The existence of halide ions also reduced analyte adsorption and enhanced stacking efficiency, resulting in greater sensitivity.

\section{Experimental}

\subsection{Chemicals and reagents}

$N$-Acetyl-L-tryptophan ( $N$-Ac-Trp), 5-amino-1-naphthol (5A-1-N), DA, E, 5-HIAA, 5-HT, HVA, naphthalene, TA, L-tryptophan (Trp), VMA, poly(vinyl pyrrolidone) (PVP) $\left(M_{\mathrm{r}}=3 \times 10^{6} \mathrm{~g} / \mathrm{mol}\right)$ and all chemicals used for preparing buffers were obtained from Aldrich (Milwaukee, WI, USA). In this study, 1.0, 10.0 and $100.0 \mathrm{mM}$ FT solutions refer to solutions consisting of 1.0, 10.0 and $100.0 \mathrm{mM}$ formic acid and Tris [tris(hydroxymethyl)aminomethane] (used to adjust the values of $\mathrm{pH}$ to 3.0-6.0), respectively.

\subsection{Apparatus}

The basic design of the CE-LINF system has been described [15]. Briefly, a high-voltage power supply (Gamma High Voltage Research Inc., Ormond Beach, FL, USA) was used to drive electrophoresis. The entire CE-LINF system was enclosed in a black box with a high-voltage interlock. High-voltage end of the separation system was put in a laboratory-made plexiglass box for safety. A diode-pumped solid-state nanolaser (JDS Uniphase, Manteca, CA, USA) that contains Nd: $\mathrm{YVO}_{4}$ medium and emits at $266 \mathrm{~nm}$ with a $5 \mathrm{~mW}$ output was used for excitation. The emission light was collected with a $10 \times$ objective (numeric aperture $=0.25$ ). One UG 1 filter from Edmund (Barrington, NJ, USA) was used to block scattered lights before the emitted light reached the photomultiplier tube (R928, Hamamatsu Photonics K.K., Shizuoka-Ken, Japan). The amplified currents were transferred directly through a $10-\mathrm{k} \Omega$ resistor to a 24-bit A/D interface (Borwin, JMBS Developments, Le Fontanil, France) at $10 \mathrm{~Hz}$ and stored in a personal computer. Capillaries (Polymicro Technologies, Phoenix, AZ, USA), $75 \mu \mathrm{m}$ I.D. $\times 365 \mu \mathrm{m}$ O.D., were used for the analysis of amines and acids without any further coating process.

\subsection{Separation}

Prior to analysis, capillaries were treated with $0.5 \mathrm{M} \mathrm{NaOH}$, $10.0 \mathrm{mM}$ FT solution ( $\mathrm{pH} 4.0$ ), or $5 \%$ PVP overnight. For 
simultaneous analysis of amines and acids in the presence of EOF, a capillary was treated with $0.5 \mathrm{M} \mathrm{NaOH}$ overnight. After $\mathrm{NaOH}$ was flushed out, the capillary was filled with $10.0 \mathrm{mM}$ FT solutions at $\mathrm{pH} 3.0,4.0,5.0$, or 6.0. After each run, the capillary was filled with $0.5 \mathrm{M} \mathrm{NaOH}$ and then was equilibrated at $1 \mathrm{kV}$ for $10 \mathrm{~min}$ to refresh the capillary wall in order to obtain a high and reproducible EOF [32,33]. For the analysis of amines in the absence of EOF under acidic conditions, capillaries were separately treated with $10.0 \mathrm{mM}$ formic acid and 5.0\% PVP overnight. Between runs, the capillaries were separately flushed with $10.0 \mathrm{mM}$ FT (pH 4.0) containing $1.0-10.0 \mathrm{mM} \mathrm{NaF}, \mathrm{KCl}$, $\mathrm{KBr}$ or $\mathrm{KI}$. When the amines were analyzed in the presence of EOF under acidic conditions ( $\mathrm{pH} 3.0-6.0$ ), the capillary was equilibrated with $0.5 \mathrm{M} \mathrm{NaOH}$ overnight and $0.5 \mathrm{M} \mathrm{NaOH}$ solutions at $25 \mathrm{~V} / \mathrm{cm}$ for $20 \mathrm{~min}$ between runs. The samples were prepared in $10.0 \mathrm{mM}$ FT solutions and the capillaries were filled with $10.0 \mathrm{mM}$ FT solutions containing $1.0-10.0 \mathrm{mM}$ $\mathrm{NaF}, \mathrm{KCl}, \mathrm{KBr}$ or $\mathrm{KI}$. Electrokinetic injection was applied at $25 \mathrm{~V} / \mathrm{cm}$ for $10 \mathrm{~s}$. The separations were carried out at $15 \mathrm{kV}$. The EOF mobilities under different conditions were determined by injecting $1 \mu \mathrm{M}$ naphthalene solution.

\subsection{Urine analysis}

Aliquots of $100.0 \mu \mathrm{L}$ urinal samples from a normal male were diluted with $900.0 \mu \mathrm{L} 10.0 \mathrm{mM}$ FT solution ( $\mathrm{pH} 4.0$ ), respectively. The capillary was separately treated with $0.5 \mathrm{M}$ $\mathrm{NaOH}$ overnight prior to use and at $25 \mathrm{~V} / \mathrm{cm}$ for $20 \mathrm{~min}$ between runs. The capillary was filled with $10.0 \mathrm{mM}$ FT (pH 4.0) containing $10.0 \mathrm{mM} \mathrm{KCl}$. Electrokinetic injection was applied at $25 \mathrm{~V} / \mathrm{cm}$ for $10 \mathrm{~s}$ and the separations were carried out at $15 \mathrm{kV}$. In order to determine the concentrations of the analytes, $5.0 \mu \mathrm{L}$ of TA $(1.0-50.0 \mu \mathrm{M}), 5$-HT $(1.0-50.0 \mu \mathrm{M})$, E $(10.0-500.0 \mu \mathrm{M})$, Trp $(10.0-500.0 \mu \mathrm{M})$, 5-HIAA $(10.0-500.0 \mu \mathrm{M})$, and HVA $(1.0-100.0 \mu \mathrm{M})$ were spiked into $495.0 \mu \mathrm{L}$ urine samples. Linear plots of the peak heights against the concentrations of the standards were depicted and the plots were used to deter- mine the concentrations of the analytes in one of the urinal samples.

\section{Results and discussion}

\subsection{Effect of halides}

The separation of biologically active amines and acids by CELINF is efficient and sensitive at low $\mathrm{pH}[17,31]$. To achieve reproducible and short separations of acids under acidic conditions ( $\mathrm{pH}<4.0$ ), treating the capillary with $\mathrm{NaOH}$ or adding $\mathrm{SiO}_{2}$ nanoparticles is essential. It has been suggested that analyte adsorption is suppressed in the presence of $\mathrm{SiO}_{2}$ nanoparticles. Unfortunately, the loss of resolution for amines generally occurs using the two approaches because of their great apparent mobilities: sum of the EOF and the EPM of amines. To optimize the resolution for amines, we tested the impact of halides on the EPM of amines in CE-LINF under acidic conditions ( $\mathrm{pH}$ 4.0-6.0). Our hypothesis is that the positive amines should migrate slowly when they form ion pairs with halides. On the basis of decreases in analyte adsorption with increasing ionic strength, analyte adsorption should be suppressed in the presence of halides. To minimize Joule heating and ionic strength dependences of EOF and the EPM of the analytes, the concentration of halides in the FT solutions should not be too high.

To test this hypothesis, we conducted the analysis of TA and 5-HT using a capillary filled with $10.0 \mathrm{mM}$ FT solution $(\mathrm{pH}$ 4.0) containing halides. In order to minimize analyte adsorption, the capillary was dynamically coated with 5.0\% PVP prior to use. Using the coated capillary, the EOF is negligible $\left(<10^{-6} \mathrm{~cm}^{2} \mathrm{~V}^{-1} \mathrm{~s}^{-1}\right)$ and thus the variation of EOF in the presence of different halides can be ignored. Table 1 list the migration time $\left(t_{\mathrm{m}}\right)$, EPM values, theoretical plates $(N)$, and resolution of the two amines using $10.0 \mathrm{mM}$ FT solutions ( $\mathrm{pH} 4.0)$ in the absence and presence of different amounts of halides. With increasing halide concentrations, their EPMs decreased and thus their migration times became longer, mainly due to

Table 1

Impacts of halides on the $t_{\mathrm{m}}, N$, and resolution of TA and 5-HT by CE-LIF in the absence of EOF

\begin{tabular}{|c|c|c|c|c|c|c|c|c|}
\hline \multirow[t]{2}{*}{ Anion } & \multirow[t]{2}{*}{ Concentration (mM) } & \multicolumn{2}{|c|}{$t_{\mathrm{m}}(\min )(\mathrm{RSD} \%)$} & \multicolumn{2}{|c|}{$\operatorname{EPM}\left(\times 10^{-4}\right)\left(\mathrm{cm}^{2} \mathrm{~V}^{-1} \mathrm{~s}^{-1}\right)$} & \multicolumn{2}{|c|}{$N(\times 1000)$} & \multirow{2}{*}{$\frac{\text { Resolution }}{\text { TA/5-HT }}$} \\
\hline & & TA & $5-\mathrm{HT}$ & TA & 5-HT & $\mathrm{TA}$ & 5-HT & \\
\hline & 0 & $3.37(3.2)$ & $3.64(3.4)$ & 3.96 & 3.66 & 10.3 & 9.8 & 2.5 \\
\hline \multirow[t]{3}{*}{$\mathrm{NaF}$} & 0.1 & 3.47 (2.4) & $3.76(2.5)$ & 3.84 & 3.55 & 22.0 & 18.3 & 2.2 \\
\hline & 1.0 & $3.58(2.3)$ & $3.86(2.3)$ & 3.72 & 3.45 & 30.0 & 27.5 & 2.4 \\
\hline & 10.0 & $4.92(2.0)$ & $5.30(2.1)$ & 2.71 & 2.52 & 78.0 & 68.0 & 3.2 \\
\hline \multirow[t]{3}{*}{$\mathrm{KCl}$} & 0.1 & $3.49(2.5)$ & $3.76(2.5)$ & 3.82 & 3.35 & 21.5 & 17.5 & 1.8 \\
\hline & 1.0 & $3.59(2.3)$ & $3.86(2.5)$ & 3.71 & 3.45 & 22.0 & 18.0 & 1.9 \\
\hline & 10.0 & $5.81(1.8)$ & $6.21(2.1)$ & 2.29 & 2.15 & 116.5 & 99.5 & 3.6 \\
\hline \multirow[t]{3}{*}{$\mathrm{KBr}$} & 0.1 & 3.31 (2.6) & $3.59(2.8)$ & 4.03 & 3.71 & 21.0 & 16.5 & 1.9 \\
\hline & 1.0 & $3.65(2.6)$ & $3.96(2.7)$ & 3.65 & 3.37 & 16.0 & 11.0 & 2.0 \\
\hline & 10.0 & $6.14(2.4)$ & $6.35(2.4)$ & 2.17 & 2.10 & 47.8 & 45.3 & 2.0 \\
\hline \multirow[t]{3}{*}{ KI } & 0.1 & $4.02(3.0)$ & $4.32(3.1)$ & 3.32 & 3.09 & 20.8 & 19.0 & 1.9 \\
\hline & 1.0 & 4.79 (2.6) & $5.14(2.7)$ & 2.78 & 2.06 & 13.3 & 8.8 & 2.7 \\
\hline & 10.0 & $6.48(2.5)$ & $6.48(2.5)$ & 2.06 & 2.06 & 43.5 & 43.5 & 0 \\
\hline
\end{tabular}

a The capillary was treated with 5.0\% PVP and filled with $10.0 \mathrm{mM}$ FT solutions (pH 4.0) containing halides. Other conditions are the same as in Fig. 1. 
increases in ionic strength and formation of ion pairs. When the ionic strength of the BGE was increased by adding salt and/or increasing BGE concentration, the zeta potential of the analytes decreased and thus the EPMs decreased. We point out that the impact of ionic strength has on the changes in the zeta potentials and thus on alternation of the EPMs is negligible at low concentration of halides $(<1.0 \mathrm{mM})$. In other words, formation of ion pairs is the main contributor for decreases in the EPMs at low ionic strength. The amines and halides that were in adjacent zones inside the capillary interacted to form ion pairs during electrophoresis because the amines and halides have positive and negative EPMs. At constant halide concentrations, the EPM values for the two amines were the highest and the smallest in the presence of fluoride and iodide, respectively. Because iodide is heavier, the amines slowed down more effectively when forming ion pairs with iodide. It is also due to great formation constant values of the amines with iodide [34]. The result supports that the formation of ion pair is the primary factor for the decreases in the EPM. With increasing halide concentration, the peak become sharper, the efficiency increased, and repeatability improved. For example, in the absence and presence of $10 \mathrm{mM} \mathrm{KCl}$, the theoretical plate numbers for TA are $10^{4}$ and $1.2 \times 10^{5}$, and the RSD values of its migration times are 3.2 and $1.8 \%$, respectively. We suggest that the improved performance is mainly due to suppression of analyte adsorption. At high salt concentration, the electrostatic interaction of the analytes with exposure $\mathrm{SiO}^{-}$and hydrogen bonding of the analytes with $\mathrm{PVP}$ is suppressed [35]. In the case of using FT solutions containing $10.0 \mathrm{mM}$ halides, stacking is another possible factor for high efficiency; the anlaytes prepared in lower conductivity media slowed down when migrated to the higher conductivity BGE. In terms of efficiency and resolution, adding $10.0 \mathrm{mM} \mathrm{KCl}$ to FT solution ( $\mathrm{pH} 4.0$ ) is suitable. We point out that adding $10.0 \mathrm{mM}$ KI to $10.0 \mathrm{mM}$ FT (pH 4.0) is improper because of the loss of resolution.

\subsection{Comparison of separations in the presence and absence of $E O F$}

For simultaneous separation of amines and acids, the separation $\mathrm{pH}$ cannot be too low $(\mathrm{pH}<3.0)$ or too high $(>6.0)$ mainly because of losses of resolution. While using the capillary coated with $5.0 \%$ PVP and filled with $10.0 \mathrm{mM}$ FT containing $10.0 \mathrm{mM}$ $\mathrm{KCl}$ (pH 3.0-6.0), only four amines can be separated as listed in Table 2. The migration times were also quite long for 5-A-1-N at $\mathrm{pH} 5.0$ and 6.0; the positively charged density of 5-A-1-N decreases with increasing $\mathrm{pH}$. In the absence of EOF, the detection of Trp at $\mathrm{pH} 3.0$ indicates that it possessed positive charges. When using a capillary treated with $10.0 \mathrm{mM}$ FT (pH 4.0), six analytes were resolved in $10.0 \mathrm{mM} \mathrm{FT} \mathrm{(pH} \mathrm{3.0)} \mathrm{within} 20 \mathrm{~min}$, indicating the existence of small EOF. The detection of 5-HIAA (neutral at $\mathrm{pH}$ 3.0) at 19.45 min supports the existence of EOF in the system. At values of $\mathrm{pH}$ greater than 3.0, 5-HIAA was not detected within $20 \mathrm{~min}$ because it migrated against small EOF.

The result listed in Table 2 suggests that a greater EOF is required for simultaneous separation of amines and acids. The electropherograms depicted in Fig. 1A-C compare the sepa-

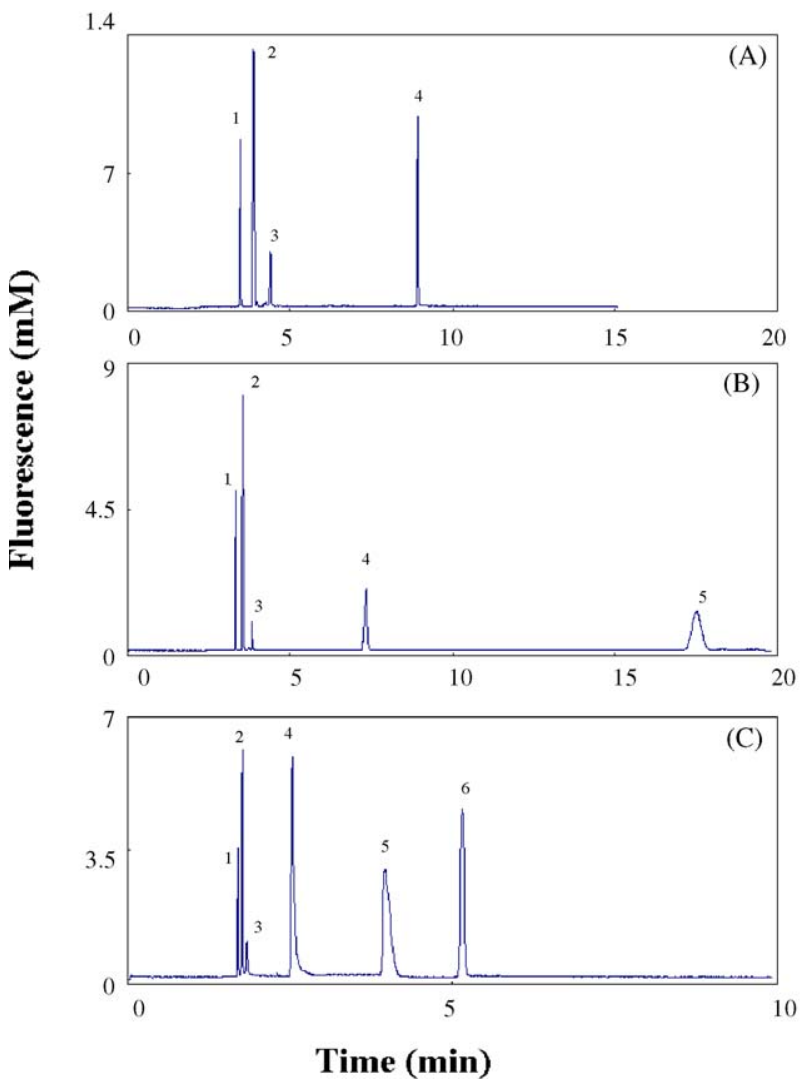

Fig. 1. Comparison of the separations of six biological amines and acids in $10.0 \mathrm{mM}$ FT solutions $(\mathrm{pH} 4.0)$ at $15 \mathrm{kV}$ by CE-LINF using capillaries treated with (A) $5.0 \% \mathrm{PVP}$, (B) $10.0 \mathrm{mM} \mathrm{FA} \mathrm{(pH} \mathrm{4.0),} \mathrm{and} \mathrm{(C)} 0.5 \mathrm{M} \mathrm{NaOH}$ overnight. The capillaries were filled with $10.0 \mathrm{mM}$ FT solution $(\mathrm{pH} 4.0)$ containing $10.0 \mathrm{mM} \mathrm{KCl}$. Samples were prepared in $10.0 \mathrm{mM}$ FT solution (pH 4.0) and injected at $1 \mathrm{kV} 10 \mathrm{~s}$. Capillary: $40 \mathrm{~cm}(30 \mathrm{~cm}$ effective length), $75 \mu \mathrm{m}$ I.D and $365 \mu \mathrm{m}$ O.D. Peak identities (concentration): (1) TA $(50.0 \mathrm{nM})$, (2) 5-HT $(0.50 \mu \mathrm{M})$, (3) 5-A-1-N $(50.0 \mu \mathrm{M})$, (4) E (5.0 $\mu \mathrm{M})$, (5) 5-HIAA (1.0 $\mu \mathrm{M})$, and (6) $\operatorname{Trp}(1.0 \mu \mathrm{M})$

rations of the six analytes using capillaries treated with $5.0 \%$ PVP, $10.0 \mathrm{mM}$ FT ( $\mathrm{pH} \mathrm{4.0),} \mathrm{and} \mathrm{0.5} \mathrm{M} \mathrm{NaOH.} \mathrm{In} \mathrm{the} \mathrm{absence}$ of EOF and small EOF, only four and five analytes were separately detected in Fig. 1A and B, respectively. Fig. 1C exhibits that the six analytes were nicely separated within $11 \mathrm{~min}$. A relatively high $\operatorname{EOF}\left(1.85 \times 10^{-4} \mathrm{~cm}^{2} \mathrm{~V}^{-1} \mathrm{~s}^{-1}\right)$ is the main reason for a fast separation. By treating the capillary with $0.5 \mathrm{M} \mathrm{NaOH}$ after each run, the silanol $(\mathrm{SiOH})$ on the capillary wall dissociated more completely to generate a bulk EOF and repeatability improved [31]. To have a bulk EOF during separation, it is also important to fill the capillary with low-ionic-strength FT solution ( $\mathrm{pH}$ 4.0). With the advantages of high EOF and fresh capillary wall, the RSD values for the migration times of the six analytes were all less than $2.2 \%(n=3)$.

When using a capillary treated with $\mathrm{NaOH}$, the migration times for the analytes (Table 2) vary at different $\mathrm{pH}$ because EOF and their EPMs both depend on $\mathrm{pH}$. The electropherograms depicted in Fig. 2A-D shows the separations of the six analytes at $\mathrm{pH} 3.0,4.0,5.0$, and 6.0, respectively. Not only the separation is long, but also there is loss of resolution for the four amines at $\mathrm{pH}$ 3.0. A long separation was due to a small bulk EOF. The 
Table 2

Effects of $\mathrm{pH}$ on the migration times for amines and acids using differently treated capillaries ${ }^{\mathrm{a}}$

\begin{tabular}{|c|c|c|c|c|c|c|c|c|c|c|c|c|}
\hline \multirow[t]{3}{*}{ Analytes $^{\mathrm{a}}$} & \multicolumn{12}{|c|}{ Migration time (min) } \\
\hline & \multicolumn{4}{|c|}{$5.0 \%$ PVP treated capillary ${ }^{b, c}$} & \multicolumn{4}{|c|}{$10 \mathrm{mM}$ FT treated capillary $\mathrm{c}, \mathrm{d}$} & \multicolumn{4}{|c|}{$\mathrm{NaOH}$ treated capillary ${ }^{\mathrm{c}, \mathrm{e}}$} \\
\hline & $\mathrm{pH} 3.0$ & $\mathrm{pH} 4.0$ & $\mathrm{pH} 5.0$ & pH 6.0 & $\mathrm{pH} 3.0$ & $\mathrm{pH} 4.0$ & pH 5.0 & $\mathrm{pH} 6.0$ & $\mathrm{pH} 3.0$ & $\mathrm{pH} 4.0$ & $\mathrm{pH} 5.0$ & $\mathrm{pH} 6.0$ \\
\hline TA & 3.46 & 3.57 & 3.76 & 3.34 & 4.96 & 3.32 & 2.52 & 2.21 & 3.85 & 1.70 & 1.26 & 1.16 \\
\hline $5-\mathrm{HT}$ & 3.75 & 3.94 & 4.09 & 3.77 & 5.21 & 3.54 & 2.66 & 2.36 & 3.85 & 1.76 & 1.31 & 1.22 \\
\hline $5-A-1-N$ & 4.03 & 4.38 & 4.47 & 4.27 & 5.39 & 3.83 & 2.83 & 2.56 & 3.85 & 1.84 & 1.37 & 1.29 \\
\hline $\mathrm{E}$ & 4.32 & 8.85 & 14.05 & 27.02 & 5.54 & 7.34 & 6.25 & 5.40 & 6.19 & 2.33 & 2.21 & 2.16 \\
\hline
\end{tabular}

${ }^{a}$ Sample were prepared in $10.0 \mathrm{mM}$ FT (pH 3.0-6.0).

b Conditions are the same as in Fig. 1A.

${ }^{c}$ Capillary was filled with $10.0 \mathrm{mM}$ FT (pH 3.0-6.0) containing $10.0 \mathrm{mM} \mathrm{KCl}$.

${ }^{\mathrm{d}}$ Capillary was treated with $10 \mathrm{mM}$ FT (pH 3.0). Other conditions are the same as in Fig. 2.

e Conditions are the same in Fig. 2.

${ }^{\mathrm{f}}$ Not detected.

peak for 5-HIAA (neutral) is broad at $\mathrm{pH} 3.0$ because it had a strong interaction with the capillary wall. At $\mathrm{pH} 5.0$ and 6.0, E and Trp were not resolved. A loss of resolution between 5HT and 5-A-1-N occurred at $\mathrm{pH} 6.0$ although the separation was slightly faster. For this reason we conducted the separation at $\mathrm{pH}$ 4.0 using a capillary treated with $\mathrm{NaOH}$ for the following study.
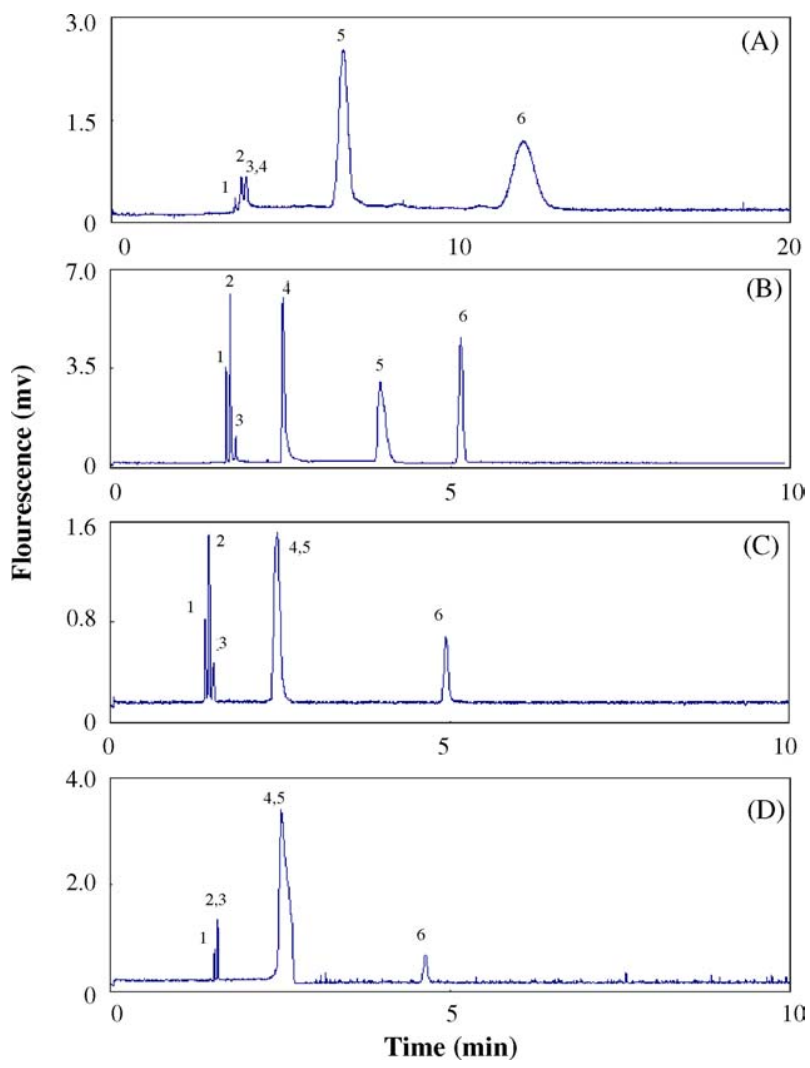

Fig. 2. Separations of six biologically active amines and acids in $10.0 \mathrm{mM}$ FT in the presence of EOF at different values of $\mathrm{pH}$. Capillary was treated with $0.5 \mathrm{M} \mathrm{NaOH}$ overnight. The capillary was filled with $10.0 \mathrm{mM}$ FT solutions containing $10.0 \mathrm{mM} \mathrm{KCl}$ at (A) $\mathrm{pH} 3.0$, (B) $\mathrm{pH} 4.0$, (C) $\mathrm{pH} 5.0$, and (D) $\mathrm{pH} 6.0$. Other conditions are the same as Fig. 1. Peak identities (concentration): (1) TA (5.0 nM), (2) 5-HT (50.0 nM), (3) E (1.0 $\mu \mathrm{M})$, (4) 5-A-1-N (50.0 $\mu \mathrm{M})$, (5) Trp $(1.0 \mu \mathrm{M})$, and (6) 5-HIAA $(1.0 \mu \mathrm{M})$.

\subsection{Limit of detection}

To further test the proposed method, we conducted the separation of ten analytes, including biologically active amines such as TA, 5-HT and E as well as acids such as 5-HIAA, HVA, and VMA. Fig. 3 shows that the 10 analytes were nicely separated within $12 \mathrm{~min}$. The peaks for amines are sharp; the numbers of theoretical plates for TA and $\mathrm{E}$ are $7.5 \times 10^{5}$ and $7.5 \times 10^{4}$, respectively. The RSD of the migration times for the 10 analytes were all less than $2.7 \%$ as a result of a fast separation and suppressed analyte adsorption in the presence of halides. When conducting the analysis using a capillary filled with $10.0 \mathrm{mM}$ FT (without $10.0 \mathrm{mM} \mathrm{KCl}$ ) at $\mathrm{pH} 4.0$, the first four peaks were not well resolved. In addition, the peaks for $N$-Ac-Trp, HVA, and VMA were quite broad (the peak widths at the base were greater than $1.7 \mathrm{~min}$ ) and the separation was less reproducible (RSD > 6.5\%). When compared to the method using PEO solution [18], this method is faster and has lower

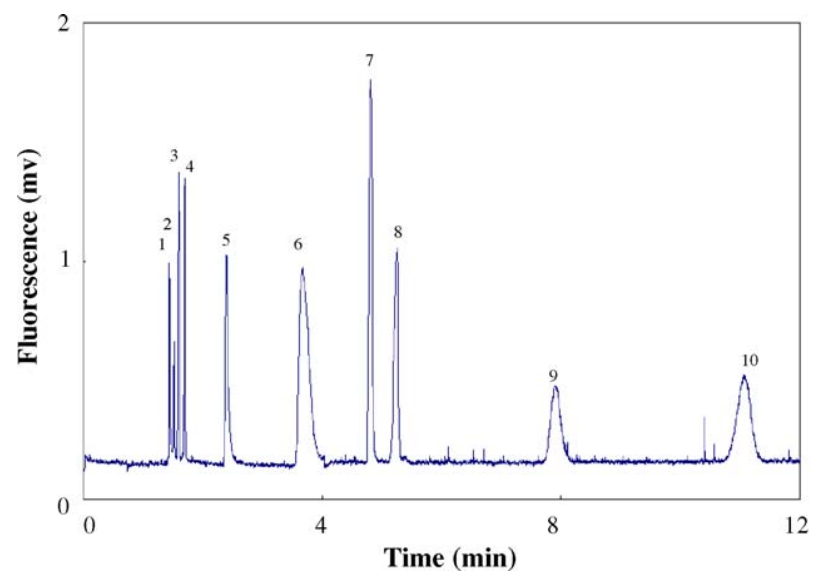

Fig. 3. Separation of 10 biologically active amines and acids in $10.0 \mathrm{mM}$ FT solution ( $\mathrm{pH} 4.0$ ) at $15 \mathrm{kV}$ by CE-LINF in the presence of EOF. Other conditions are the same as Fig. 2. Peak identities (concentration): (1) TA (5.0 nM), (2) 5-HT (50.0 nM), (3) DA $(0.50 \mu \mathrm{M})$, (4) E $(5.0 \mu \mathrm{M})$, (5) 5-A-1-N (1.0 $\mu \mathrm{M})$, (6) Trp (10.0 nM), (7) 5-HIAA $(0.50 \mu \mathrm{M}),(8) N$-Ac-Trp $(0.50 \mu \mathrm{M})$, (9) HVA $(10.0 \mu \mathrm{M})$, and (10) VMA $(50.0 \mu \mathrm{M})$. 
Table 3

The biological relevance and concentrations of six markers in urine ${ }^{\mathrm{a}}$

\begin{tabular}{|c|c|c|c|c|}
\hline Analyte & Normal level $^{b}$ & Linear regression $^{\mathrm{c}}$ & $R^{2}$ & Concentration $(\mu \mathrm{M})$ \\
\hline TA & $6.4 \mu \mathrm{g} /$ day $(0.1-0.4 \mu \mathrm{M})$ & $Y=129.62 X+413.95$ & 0.9938 & $0.3(3.3)^{\mathrm{d}}$ \\
\hline $5-\mathrm{HT}$ & $146 \mu \mathrm{g} /$ day $(<0.9 \mu \mathrm{M})$ & $Y=303.67 X+352.83$ & 0.9963 & $0.12(3.1)$ \\
\hline $\mathrm{E}$ & & $Y=385.95 X+194.62$ & 0.9971 & $50.0(3.2)$ \\
\hline $\operatorname{Trp}$ & $25.5 \mathrm{mg} /$ day $(\sim 60 \mu \mathrm{M})$ & $Y=563.52 X+5207.7$ & 0.9999 & $92.4(3.5)$ \\
\hline 5-HIAA & $2 \mathrm{mg} /$ day $(<50 \mu \mathrm{M})$ & $Y=562.4 X+1335.7$ & 0.9938 & $23.7(2.8)$ \\
\hline HVA & 6 mg/day $(<40 \mu \mathrm{M})$ & $Y=270.14 X+235.64$ & 0.9936 & $8.7(3.9)$ \\
\hline
\end{tabular}

a The experimental condition is the same as Fig. 4.

b The data are taken from ref. [18,31,36-38].

c $Y$ represents peak height $(v)$ and $X$ represents the concentrations of spiked analytes.

d $\% \operatorname{RSD}(n=3)$.

fluorescence background. This method also provides a stable baseline and lower background than does that under discontinuous conditions [19]. As a result, this method is more sensitive for the analytes, with the LODs at the sub-nM level for most analytes (without stacking). For example, the LODs at S/N 3 for TA, 5-HT, DA, E, 5-A-1-N, Trp, 5-HIAA, $N$-Ac-Trp, HVA and VMA are $0.1,2.1,8.1,84.2,23.0,0.3,6.2,11.3,670$, and $3000 \mathrm{nM}$, respectively.

\subsection{Analysis of urine}

Having a high resolving power and sensitivity, this method should be useful for analysis of biologically active amines and acids in biological samples. To test the feasibility of the present method, we conducted the analysis of urine samples. Fig. 4 shows one representative electropherogram. Several peaks including TA, 5-HT, E, Trp, 5-HIAA, and HVA were identified. When compared to the analysis of the standard sample (Fig. 3), the migration times for Trp, HIAA, and HVA were different, showing matrix effects. We note that the ionic strength, $\mathrm{pH}$, and species in the diluted urine sample are quite different from the standard solution. Since we used a UV laser as the light source, the unidentified peaks should correspond to solutes with native fluorescence in the UV range, including benzoic compounds, polycyclic aromatic hydrocarbon, heterocyclic

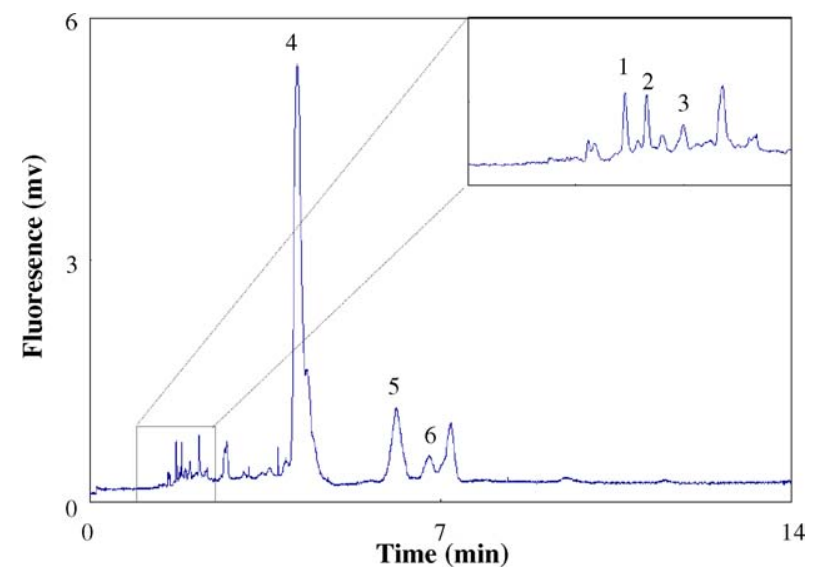

Fig. 4. Analysis of a diluted urine sample by CE-LINF in the presence of EOF. Conditions are the same as Fig. 3. Peak identities: (1) TA, (2) 5-HT, (3) E, (4) Trp, (5) 5-HIAA, and (6) HVA. compounds, peptides containing Trp, tyrosine, and phenylalanine residues, nucleotides, oligonucleotides, and so on. Owing to less interferences and high sensitivity of the present approach, sample pretreatment is not required. Without sample pretreatment, the method is reproducible; RSD of migration times for the identified analytes is less than $3.1 \%$. On the basis of the peak heights and the regression lines shown in Table 3, the concentrations of TA, 5-HT, E, Trp, 5-HIAA, and HVA in one of the urine samples were determined. The results listed in Table 3, which are in good agreement with the literature [18,31,36-38]. We note that scientists have made great efforts to determine catecholamines, HVA and VMA, the major metabolites of catecholamines, in urine for neurologic diagnosis and for monitoring the response of therapy in illnesses such as neuroblastoma and phaeochromocytoma [11]. The result suggests a great potential of this method for diagnosis and neuron study.

\section{Conclusions}

Simultaneous analysis of biologically active amines and acids by CE-LINF under acidic conditions has been reported. In order to achieve rapid and reproducible analysis of the analytes at $\mathrm{pH}$ 4.0 , the capillary must be treated with $0.5 \mathrm{M} \mathrm{NaOH}$ prior to and after analysis. The CE-LINF approach allows detection of most of the analytes at $\mathrm{nM}$ level. The formation of ion pairs between the amines and halides is useful for optimum resolution of the amines, which opens the possibility of simultaneously optimizing resolution and speed for anionic and cationic analytes by using BGEs containing cations and anions that can form ion pairs with analytes. The results shown in this study suggest that the present method hold great potential for diagnostic purposes and neuron study. In order to detect trace amines such as TA, 5HT, and E in biological samples such as brain microdialysates, a stacking approach such as field amplification has to be applied. In order to achieve great stacking efficiency, desalting prior to analysis or adding a plug of organic solvent after sample injection is needed when conducting a stacking approach based on ion-pair formation.

\section{Acknowledgement}

This work was supported by the National Science Council of Taiwan (NSC 93-2113-M-242-006). 


\section{References}

[1] K. Vuorensola, H. Sirén, R. Kostiainen, T. Kotiaho, J. Chromatogr. A 979 (2002) 179

[2] X. Páez, L. Hernández, Biopharm. Drug Dispos. 22 (2001) 273.

[3] I.R. White, E.J. Brunner, J.L. Barron, J. Clin. Epidemiol. 48 (1995) 263.

[4] K. Vuorensola, H. Sirén, J. Chromatogr. A 895 (2000) 317.

[5] K. Vuorensola, H. Sirén, U. Karjalainen, J. Chromatogr. B 788 (2003) 227.

[6] C. Rajda, K. Bencsik, L. Vécsei, J. Bergquist, J. Neuroimmunol. 124 (2002) 93

[7] M.A. Raggi, C. Sabbion, G. Casamenti, G. Gerra, N. Calonghi, L. Masotti, J. Chromatogr. B 730 (1999) 201.

[8] R.P.H. Nikolajsen, A.M. Hansen, Anal. Chim. Acta 449 (2001) 1.

[9] H. Sirén, M. Mielonen, M. Herlevi, J. Chromatogr. A 1032 (2004) 289.

[10] M.-M. Hsieh, Y.-C. Kuo, M.-j. Lyu, H.-T. Chang, J. Chromatogr. A 898 (2000) 133.

[11] A. García, M. Heinänen, L.M. Jiménez, C. Barbas, J. Chromatogr. A $871(2000) 341$

[12] S. Hu, N.J. Dovichi, Anal. Chem. 74 (2002) 2833.

[13] S. Oguri, J. Chromatogr. B 747 (2000) 1.

[14] K.D. Altria, D. Elder, J. Chromatogr. A 1023 (2004) 1.

[15] W.-L. Tseng, Y.-W. Lin, H.-T. Chang, Anal. Chem. 74 (2002) 4828.

[16] X. Sun, X. Yang, E. Wang, J. Chromatogr. A 1005 (2003) 189.

[17] S. Xiong, H. Han, R. Zhao, Y. Chen, G. Liu, Biomed. Chromatogr. 15 (2001) 83.
[18] M.-M. Hsieh, C.-E. Hsu, W.-L. Tseng, H.-T. Chang, Electrophoresis 23 (2002) 1633

[19] M.-M. Hsieh, H.-T. Chang, Electrophoresis 26 (2005) 187.

[20] D.A. Román, A.S. Carretero, C.C. Blanco, A.F. Gutiérrez, Biomed. Chromatogr. 18 (2004) 422.

[21] M. Du, V. Flanigan, Y. Ma, Electrophoresis 25 (2004) 1496.

[22] M. Molina, M. Silva, Electrophoresis 23 (2002) 2333.

[23] H.-T. Chang, E.S. Yeung, Anal. Chem. 67 (1995) 1079.

[24] X. Zhang, J.V. Sweedler, Anal. Chem. 73 (2001) 5620.

[25] K.C. Chan, G.M. Muschik, H.J. Issaq, J. Chromatogr. A 718 (1995) 203.

[26] M. Grob, F. Steiner, Electrophoresis 23 (2002) 1865.

[27] M.D. Cantu, S. Hillebrand, E. Carrilho, J. Chromatogr. A 1068 (2005) 203.

[28] J.P. Quirino, M.T. Dulay, R.N. Zare, Anal. Chem. 73 (2001) 5557.

[29] J. Horvath, V. Dolník, Electrophoresis 22 (2001) 644.

[30] C.-Y. Liu, Electrophoresis 22 (2001) 612.

[31] I.-T. Kuo, Y.-F. Huang, H.-T. Chang, Electrophoresis 26 (2005) 2643.

[32] M.-M. Hsieh, H.-T. Chang, J. Chromatogr. A 793 (1998) 145.

[33] M.-M. Hsieh, H.-T. Chang, J. Chromatogr. A 817 (1998) 129.

[34] P.R. Haddad, P.E. Jackson, J. Chromatogr. Lib., vol. 46, Elsevier, Amsterdam, 1990.

[35] Q. Gao, E.S. Yeung, Anal. Chem. 70 (1998) 1382.

[36] D.M. Paquette, R. Sing, P.R. Banks, K.C. Waldron, J. Chromatogr. B 714 (1998) 47.

[37] H. Sirén, U. Karjalainen, J. Chromatogr. A 853 (1999) 527.

[38] J. Caslavska, E. Gassmann, W. Thormann, J. Chromatogr. A 709 (1995) 147. 